\title{
STUDY OF STRUCTURAL IRREGULARITES IN HIGH RISE BUILDINGS WITH P $\triangle$ EFFECT
}

\author{
V.Guruprasad ${ }^{1}$, Arunkumar.B.N ${ }^{2}$ \\ ${ }^{1}$ Post Graduate Student \& Department of Civil Engineering, The Oxford College of Engineering \\ ${ }^{2}$ Assistant Professor \& Department of Civil Engineering, The Oxford College of Engineering
}

\begin{abstract}
In this thesis a detailed study on the behavior of structural irregularities in high rise building with and without the influence of PA effect has been carried out using E-TABS 2015 software package. in order to study the behavior of both plan irregularity (i.e. C, $L, H, T$ shapes plans), vertical irregularity (i.e. stiffness, geometric and mass irregularity) and also conventional rectangular shape, models with 5different storey heights (i.e. G+9, G+14, G19, G 24, and G+29) are modeled in E-TABS satisfying the irregularity criteria as per codes. And was analyzed by static method (Cp-coefficient method) for a basic wind speed of $50 \mathrm{~m} / \mathrm{s}$, on the other side dynamic wind analysis by Gust factor method was done by calculating Gust values for each model and $K_{2}$ coefficient for each floor heights to study the effect of Fz i.e. along wind load and cross wind forces on the structural irregularity

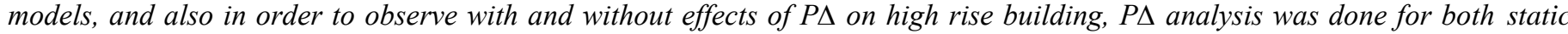
and dynamic analysis. As a result based on the storey displacement, moments and storey drift it was observed that the structures with irregularity configurations are $40 \%$ more prone to destabilizing stresses i.e. 1.4 times more when compared to conventional rectangular non-irregularity structure and also was observed that dynamic stresses is 1.7 times more than the linear static method of wind analysis.
\end{abstract}

Keywords: P- $\Delta$, Structure Irregularity, E-TABS, Cp-Coefficient Method, Gust Factor.

\section{INTRODUCTION}

From past 1.5 decade the number of tall structures and sky scrapers around the world has increased drastically, which is serving many purpose like residential, offices and many other commercial requirements. Beautiful aesthetic appearance and eye catching shapes and projections of the structures has increased the demand of tall structures. In the perspective of structural engineer designing such eye catching shapes and projections in high rise structures is a challenging job to study the behavior of structure. A sufficient tall structure or high rise building is subjected to lateral forces apart from the load of its components. There can be secondary effect on the member due to these forces. One of these forces give rise to p-delta effect,which is geometric non-linearity. This can be influenced by various condition like irregularity in structure mass and stiffness.

It causes a destabilizing moments.

Structure in real life are flexible and cause a large lateral displacement in unusual circumstances. The lateral displacement is caused by wind, vertical loads and seismic loads. In structure particularly ground reactions results to $\mathrm{p}$ delta effect.

Wind creates inward and leeward forces. This forces make building unstable forcing it apart if it is too weak to resist it. Such structure should be designed for p-delta.

\subsection{P-Delta}

In structural engineering, the P- $\Delta$ effect denotes the abrupt change in the response of Overturning moment, ground shear and axial force distribution at the base of the high rise structure or components of the structure when subject to a lateral displacement.

In general Structural designers use linear static method for analysis, which is a first order analysis, were as p delta is the second order,P Delta analysis is quite a traditional form of force follower analysis. It is also known as "Geometric Nonlinearity" because as the deflection increases you again have to test the additional forces generated by P-delta effects. A force follower analysis is the one in which, when a member loses its stability the force follows the deformed member and creates further more instability very quickly. A P-Delta analysis is not as simple as it sounds and its effects will be very adverse if neglected. These effects will be more severe in case of soft lateral force resisting systems like moment frames as compared to stiff systems like core wall systems and braced frames.Talking about P-Delta, $\mathrm{P}$ delta is a term coined from $\mathrm{P}$ that is load and delta is the lateral deformation. These lateral deformations are more lethal in case of earthquakes load for all structures and wind load for high rise buildings.

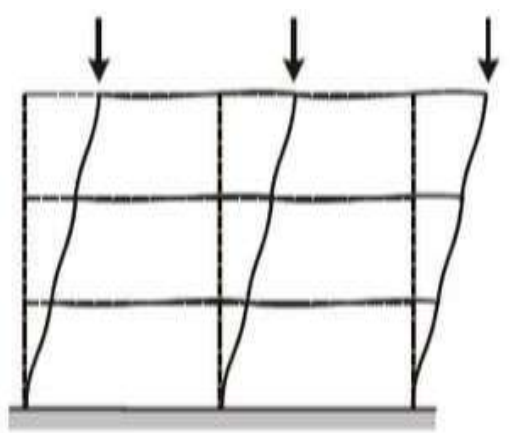

Fig 1: Behaviourof structure under lateral load 
P- $\boldsymbol{\delta}$ effect, or P-"small-delta", is associated with local deformation relative to the element chord between end nodes. Typically, $\mathrm{P}-\delta$ only becomes significant at unreasonably large displacement values, or in especially slender columns. So long as a structure adheres to the slenderness requirements pertinent to earthquake engineering, it is not advisable to model $\mathrm{P}-\delta$, since it may significantly increase computational time without providing the benefit of useful information. An easier way to capture this behavior is to subdivide critical elements into multiple segments, transferring behavior into P- $\Delta$ effect. The image below shows on the left, $\mathrm{P}-\delta$ effect and on the right P- $\Delta$ effect.
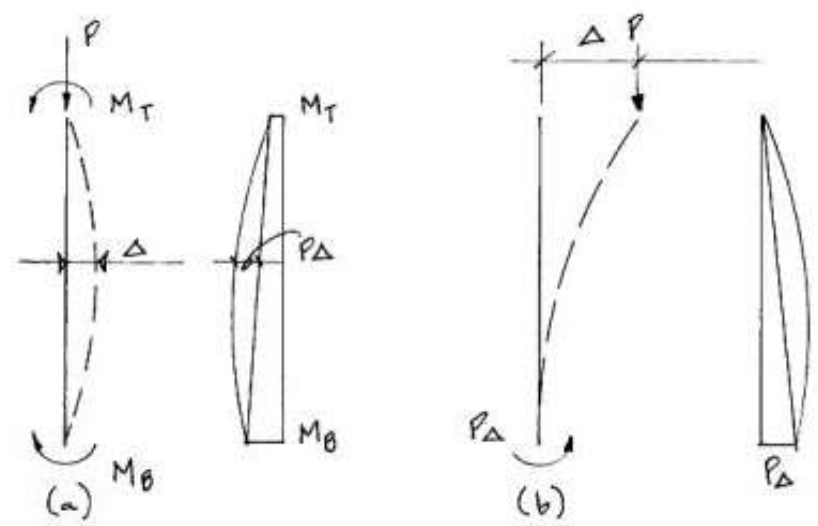

Fig 2: Influence of $\mathrm{p} \Delta$ on column

\subsection{Structural Configurations}

The configuration of the structure has considerable effect in the seismic performance of structures during earthquakes and also due to wind loads in case of tall structures. Past studies shows that structure with irregular configurations are more susceptible than with regular ones. In order to prevent the failure of structures a conceptual design is mandatory at an early stage. In addition to that, the assessment of the structural configuration is vital to achieve adequate lateral load performance.

The impact of structural configuration depends on different aspects of building forms such as height of the building, horizontal size, proportion and symmetry.

\subsubsection{Codal Provisions for Irregularity}

The section 7 of IS 1893(part1):2002 enlists the irregularity in buildings. These irregularities are categorized as follows 1. Vertical irregularities referring to sudden change of strength, stiffness, geometry and mass results in irregular distribution of forces or distribution over the height of the building.

2. Plan irregularities which refer to asymmetrical plan shapes(L-,T-,U-,RECT-) or discontinuities in the horizontal resting elements (diaphragms) such as cut-outs, large openings, re-entrant corners and other abrupt changes resulting in torsion, diaphragm deformations and stress concentration.
Vertical irregularities are classified in the Indian Standards IS 1893:2002 as follows:

a) Stiffness Irregularity

b) Mass Irregularity.

c) Vertical Geometric Irregularity.

d) Plan irregularities.

\section{METHODOLOGY}

1. Simple Static Approach

2. Dynamic Analysis (Gust Factor Method)

\section{Simple Static Approach}

This method follows mode static-method of estimating wind-load it accounts the effect of gusting and local extreme pressure on the face of the structure.it also accounts for local difference in exposure between the open countryside and a city center, as well as allowing for vital facilities such as hospitals and fire and police stations, whose safety must be ensured for use after an extreme windstorm.

\section{Dynamic Analysis (Gust Factor Method)}

Gust factor method is only the method of calculating load along wind or drag load by using gust factor method is given in the code since methods for calculating load across-wind or other components are not fully matured for all types of structures. However, it is permissible for a designer to use gust factor method to calculate all components of load on a structure using any available theory. However, such a theory must take into account the random nature of atmospheric wind speed.

Criteria to satisfy for the requirement of dynamic analysis as per IS875-3

Case1: If height to least lateral dimension ratio $>5$.

$$
\frac{90}{24}=3.75<5
$$

$\therefore$ Structure is safe hence dynamic analysis isnot required

Case 2: If natural frequency(f) $<1.0 \mathrm{~Hz}$

$$
\mathrm{T}=\frac{0.09 \mathrm{H}}{\sqrt{\mathrm{d}}}=\frac{0.09 \times 90}{\sqrt{24}}=1.65, \mathrm{f}=\frac{1}{\mathrm{~T}}=\frac{1}{1.65}=0.60
$$

$\therefore$ Hence dynamic analysis is required for $G+19, G+24$ and G+29.

\subsection{Plan Details}

The layout of the plan having $6 \times 4$ bays of length of $4 \mathrm{~m}$. The structure is considered as OMRF (ordinary moment resisting frames) of $\mathrm{G}+9, \mathrm{G}+14, \mathrm{G}+19, \mathrm{G}+24, \mathrm{G}+29$ storeys with dissimilar irregular configurations. The height of the storey is uniform throughout for all models used in analysis. ETABS 2015 software package has been used for the analysis of OMRF models. 


\subsection{Parameters Considered for Analysis}

1) Structure type: OMRF (CLASS C for wind analysis)

2) Number of stories: $G+9, G+14, G+19, G+24, G+29$

3) Floor height: $3 \mathrm{~m}$

4) Grade of concrete: $30 \mathrm{Mpa}$

5) Grade of steel: fe 415

6) Size of column: $900 \times 900 \mathrm{~mm}$

7) Size of Beam: $300 \times 600 \mathrm{~mm}$

8) Depth of slab: $150 \mathrm{~mm}$

9)Diaphragm Type: Rigid Diaphragm

10) Dead load: $1.5 \mathrm{KN} / \mathrm{m}^{2}$

11) Impose load: $2 \mathrm{KN} / \mathrm{m}^{2}$

12) Assumed city: Madras (Chennai)

13) Basic Wind speed: $50 \mathrm{~m} / \mathrm{s}$

14) Terrain category: Type 2

\section{Criteria to Satisfy Irregularity Conditions}

Plan Irregularity

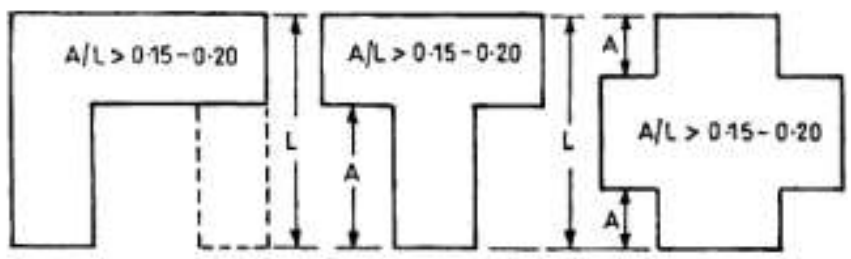

Fig 3.1 Plan irregularity

CASE 1: C Type- $A=12, L=24 \rightarrow \frac{12}{24}=0.5$

CASE 2: H Type- $A=12, L=36 \rightarrow \frac{12}{36}=0.33$

CASE 3: $\mathrm{L}$ Type- $\mathrm{A} 1=24, \mathrm{~L} 1=36 \rightarrow \frac{24}{36}=0.667 \& \mathrm{~A} 2=8$, $\mathrm{L} 2=24 \rightarrow \frac{8}{24}=0.33$

CASE 4: $\mathrm{T}$ Type- $\mathrm{A} 1=12, \mathrm{~L} 1=24 \rightarrow \frac{12}{24}=0.5 \& \mathrm{~A} 2=12$, $\mathrm{L} 2=36 \rightarrow \frac{12}{36}=0.33$

\section{Vertical Irregularity}

B1.Vertical geometrical irregularity
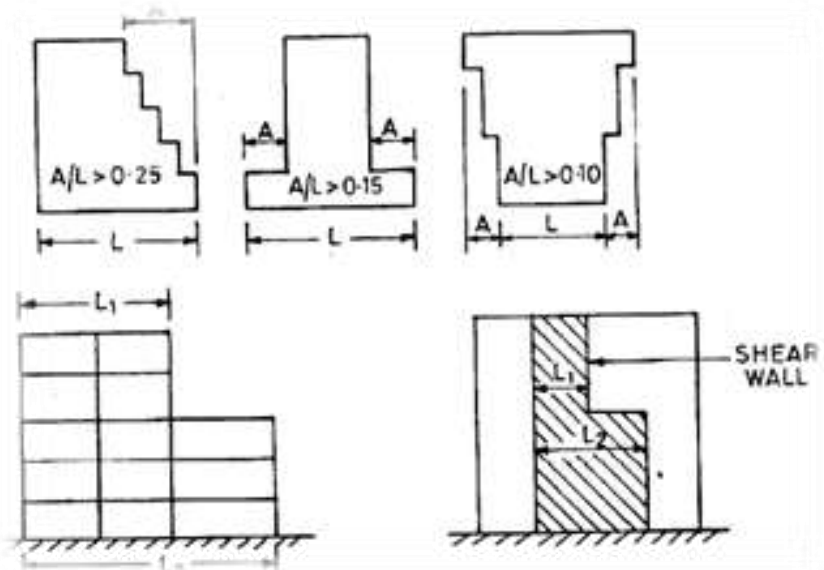

CASE 1: $50 \%$ reduction @50\% height $\rightarrow \mathbf{L}_{\mathbf{2}}=\mathbf{3 6 m}$, $\mathrm{L}_{\mathbf{1}}=\mathbf{1 8 m}, \mathrm{A}=\mathbf{1 8 m}$

$\left(\mathrm{L}_{2}>1.5 \mathrm{~L}_{1}\right) \rightarrow(36 \mathrm{~m}>1.5 \mathrm{X} 18 \mathrm{~m})$

$\frac{A}{L}>0.25 \rightarrow \frac{18}{36}=0.5>0.25$

CASE 2: 1 Bay reduction at every 5storey interval => $\mathrm{L}_{2}=36 \mathrm{~m}, \mathrm{~L}_{1}=12 \mathrm{~m}, A=24 \mathrm{~m}$

$\mathrm{L}_{2}>1.5 \mathrm{~L}_{1} \rightarrow 36 \mathrm{~m}>1.5 \mathrm{X} 12 \mathrm{~m}$

$\frac{A}{L}>0.25 \rightarrow \frac{24}{36}=0.667>0.25$

\section{B2.Vertical Stiffness Irregularity}
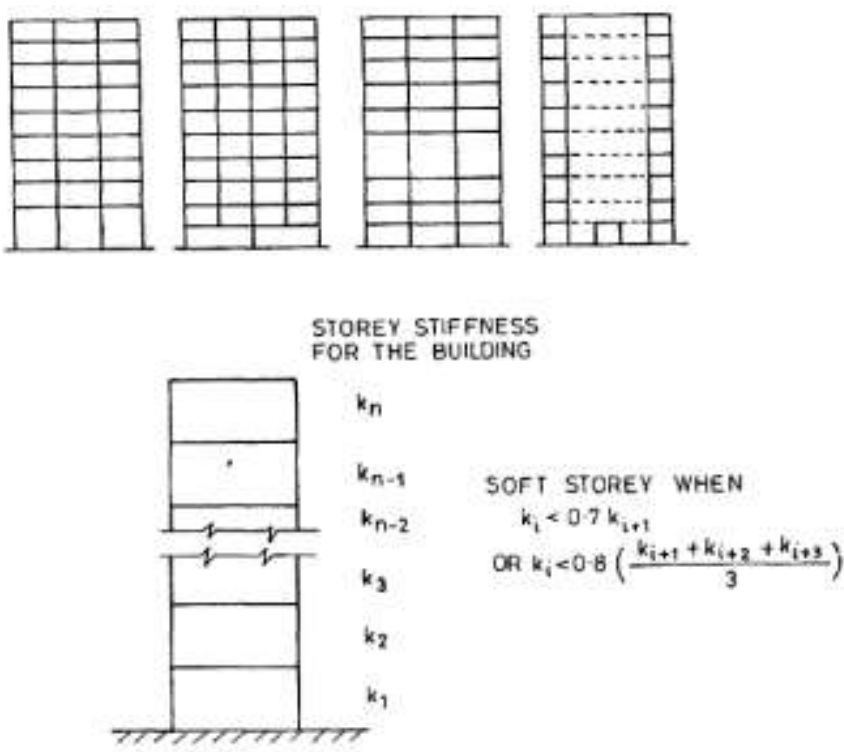

Fig 3.3 Vertical stiffness irregularity

CASE 1: Bottom storey stiffness $\left(K_{1}\right)$ column length increased by 2 times

$\mathrm{K}_{1}=\frac{12 E I}{L^{3}}=\frac{12 E I}{6^{3}}=0.055 \mathrm{EI}$

$\mathrm{K}_{2}=\frac{12 E I}{L^{3}}=\frac{12 E I}{3^{3}}=0.44 \mathrm{EI}$

$\mathrm{K}_{1}<0.7 \mathrm{~K}_{2}$

CASE 2: Mid storey stiffness (Ki) column length increased by 2 times

$\mathrm{Ki}=\frac{12 E I}{L^{3}}=\frac{12 E I}{6^{3}}=0.055 \mathrm{EI}$

$\mathrm{Ki}+1=\frac{12 E I}{L^{3}}=\frac{12 E I}{3^{3}}=0.44 \mathrm{EI}$

$\mathrm{Ki}<0.7 \mathrm{Ki}+1$

CASE 3: Extreme soft storey (Average stiffness of storey (Ki))

Fig 3.2 Vertical geometric irregularity 
Two full bay of columns last but one were removed on either side to create floating columns condition in the model.

Bottom Storey stiffness $K_{1}=25$ columns $x \mathrm{~K}=25 \times \frac{12 E I}{3^{3}}=11 \mathrm{EI}$

Storey stiffness $\mathrm{K}_{2}=35$ columns $\times \mathrm{K}=35 \times \frac{12 E I}{3^{3}}=15.8 \mathrm{EI}$

$\mathrm{K}_{1}<0.7 \mathrm{~K}_{2}$

B3.Mass Irregularity

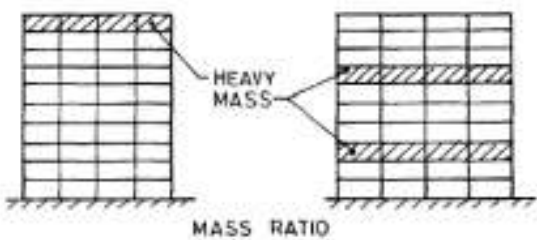

Fig 3.4 Mass irregularity

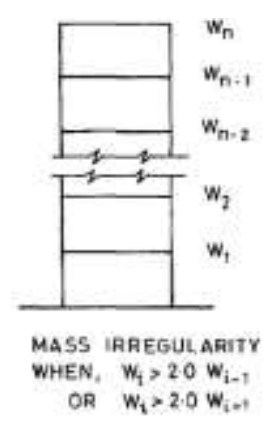

HEN, $W_{i}>20 w_{i-1}$
CASE 1: Mid storey mass increased by 2times

To increase the mass in the mid height of the structure the slab thickness is increased by 2 times at mid storey of the structure with respect to the total number of storey and in case of even number of total storey the adjacent floor to the mid height of the structure.

\subsection{Static Method}

Static method is the simplest method of wind analysis carried out on base of IS code

IS 875 part 3.In the software package ETABS2015 static wind analysis is the simplest wind analysis in which the wind loads and Cp coefficients are applied through RIGED DIAPHRAGMS.

Following are the values required for the analysis

1) Wind speed $\mathrm{Vb}=50 \mathrm{~m} / \mathrm{s}$

2) Risk coefficient (K1 Factor) $=1$

3) Topography (K3 Factor) $=1$

4) External pressure Coefficient $(\mathbf{C p e})=1.2$

Building height ratio $\frac{h}{W}=\frac{90}{24}=3.75$, Building plan ratio $\frac{L}{W}=\frac{36}{24}=1.5$

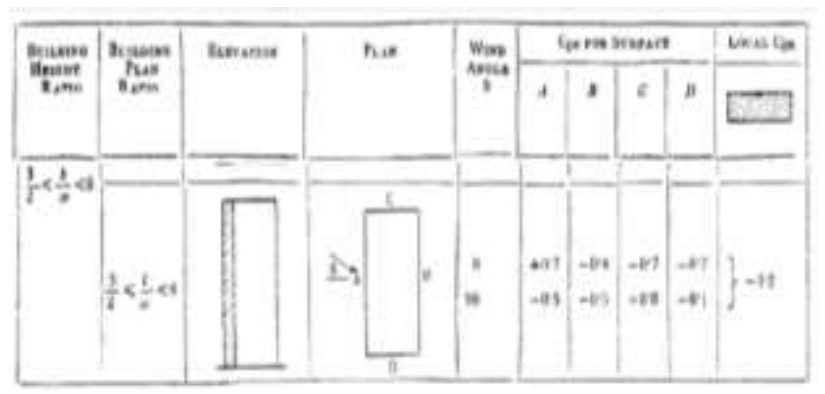

Fig 4: Cp coefficents from IS875-3
Using the above calculated external pressure coefficients (Cpe) the windward (Cp) and leeward (Cp) coefficients are found from code IS 875 part3 Table 4 based on the calculated "Building height ratio" and followed by "Building plan ratio" with respect to the face A,B,C,D and wind angle $\theta$ i.e... $0^{\circ}$ and $90^{\circ}$

The above values are inputs to perform the static wind analysis in Etabs and the required analyzed results are obtained.

\subsection{Dynamic Analysis (Gust Factor Method)}

Gust factor method is a dynamic wind analysis which is the most realistic and reliable theoretical analysis carried out based on the gust effects caused by wind on the high rise structures.

In this method of analysis the gust factor is calculated as follows for the above given models,

1) Regional basic wind speed $\mathrm{Vb}=50 \mathrm{~m} / \mathrm{s}$

2) Hourly mean wind speed $(\mathrm{m} / \mathrm{s})$ at height $\mathrm{z}$

3) Probability factor $(\mathrm{K} 1)=1$

4) Terrain and height factor (K2 Factor)

5) Topography factor $(\mathrm{K} 3)=1$

\section{$\underline{\text { Design hourly mean wind speed }}$}

$\left.V z=V b \times K_{1} \times K_{2} \times K_{3} V(h)=\underset{/ s}{V(z m i n}\right)=50 X 1 X 0.67 X 1=33.5 m$

Design pressure at height $z$ due to hourly mean wind speed

$$
\mathrm{Pz}=0.6(\mathrm{Vz})^{2}
$$

\section{Computation of gust factor (G)}

$$
\mathrm{G}=1+\operatorname{gfr} \sqrt{\left[B(1+\emptyset)^{2}+\frac{S E}{\beta}\right]}
$$

Case 1: Gust factor for height $90 \mathrm{~m} \mathrm{X}$ direction wind $0^{\circ}$ $\mathbf{G}=\mathbf{2 . 0 3}$

Case 2: Gust factor for height $90 \mathrm{~m} \mathrm{Y}$ direction wind $90^{\circ}$ $\mathbf{G}=\mathbf{2 . 1 4 1}$

Case 3: Gust factor for height $75 \mathrm{~m} \mathrm{X}$ direction wind $0^{\circ}$ $\mathbf{G}=\mathbf{2 . 1 2}$

Case 4: Gust factor for height $75 \mathrm{~m} \mathrm{X}$ direction wind $90^{\circ}$ $\mathbf{G}=\mathbf{2 . 2 0}$

Case 5: Gust factor for height $60 \mathrm{~m} \mathrm{X}$ direction wind $0^{\circ}$ $\mathbf{G}=\mathbf{2 . 2 0 3}$

Case 6: Gust factor for height $60 \mathrm{~m} \mathrm{X}$ direction wind $90^{\circ}$ $\mathbf{G}=\mathbf{2 . 2 5 4}$

Effective area (Ae)

$6 \mathrm{X} 3=18 \mathrm{~m}^{2}$ for both faces an all frames

Force coefficient $(\mathrm{C} f)$

Short face-after body orient wind 


$$
\frac{a}{b}=\frac{36}{24}=1.5, \frac{h}{b}=\frac{90}{24}=3.75
$$

Based on the above values force coefficient $(C f)$ was observed to be 1.25 for short face of the building.

\section{Long face-after body orient wind}

$$
\frac{a}{b}=\frac{24}{36}=0.66, \frac{h}{b}=\frac{90}{36}=2.5
$$

Based on the above values force coefficient $(C f)$ was observed to be 1.20 for long face of the building.

$$
\text { F }=\text { C } \boldsymbol{f} \text {. Ae. Pz. G }
$$

The gust factor ,effective area, force coefficient was calculated, the wind force was determined using above formula with respect to $\mathrm{K}_{2}$ factor (Hourly mean wind speed factor) for respective floor height as per table 33 P49 IS8753 . And the calculation was carried out using MS. Excel. Thus the table obtained is shown below.

\section{RESULTS AND DISCUSSIONS}

The analyzed results and discussions of wind analysis of irregular RC framed structure. The results of both $\mathrm{Cp}$ coefficient method (Static wind analysis) and Gust factor method (Dynamic wind analysis) for plan irregularities as well as vertical irregularity models has been discussed below.

\subsection{Displacement}

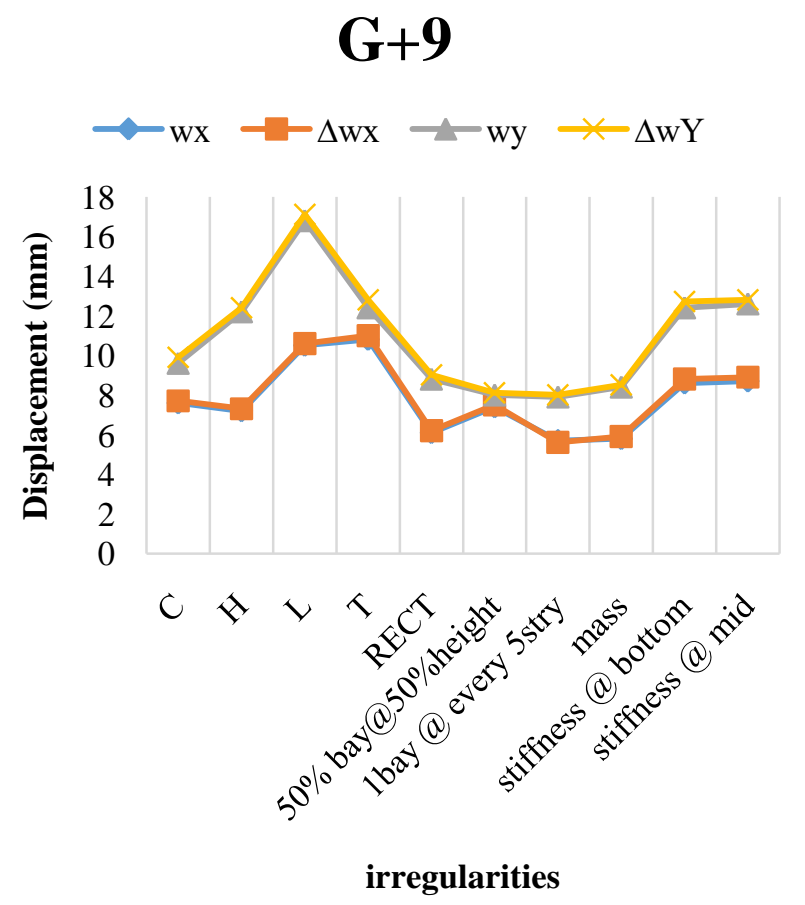

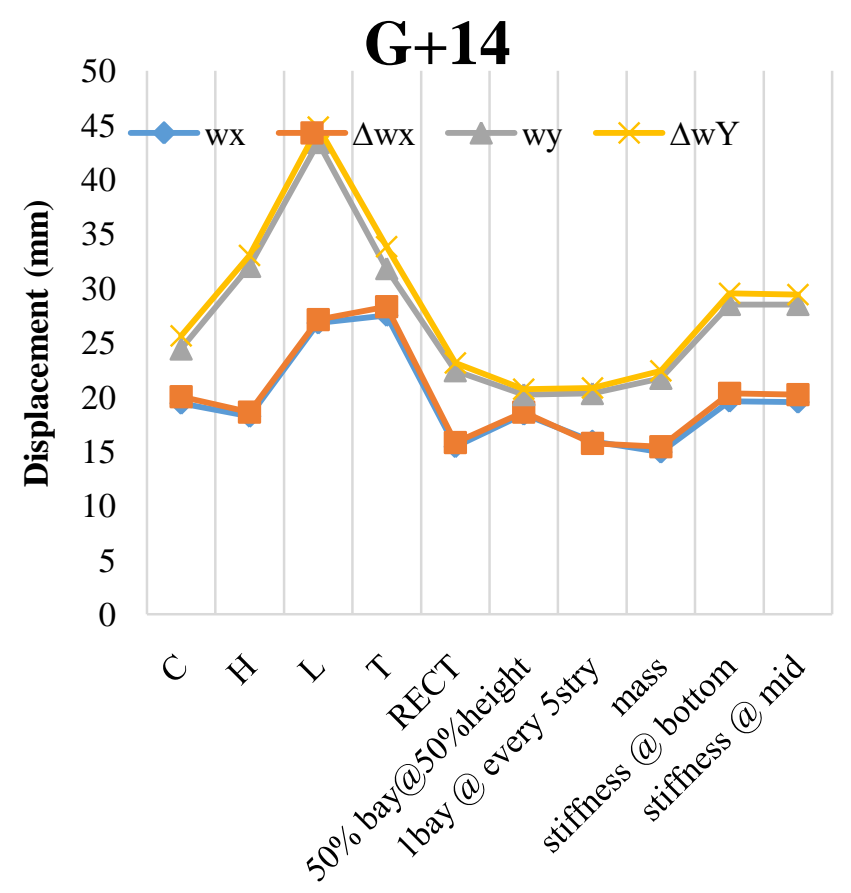

Irregularities

Fig 18. Static displacement of G+14 for all irregularities

\section{G+19}

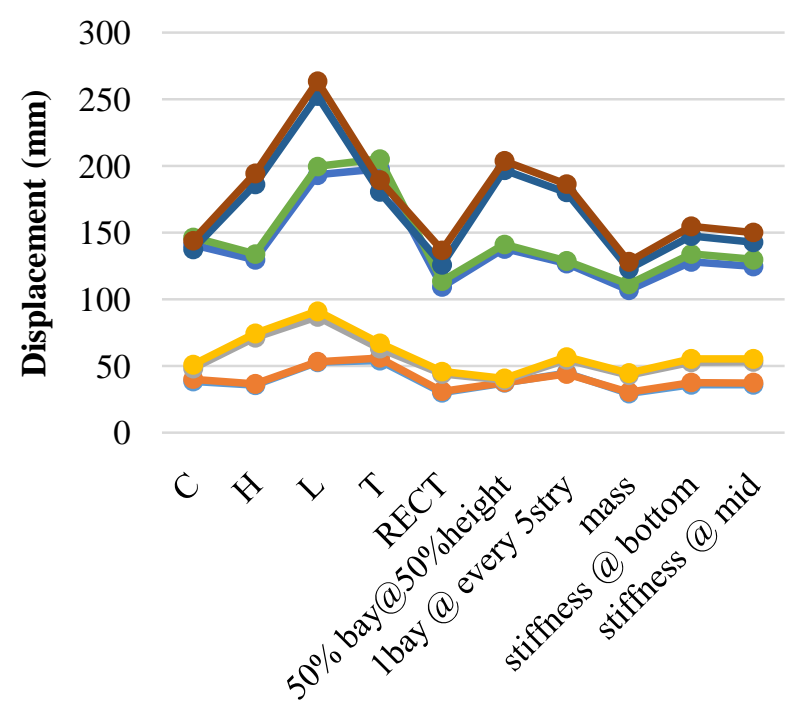

Irregularities

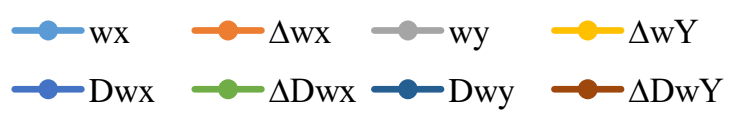

Fig 19.Static and dynamic analysis displacement of G+19 for all irregularities

Fig 17.Static analysis displacement of G+9 for all irregularities 


\section{$\mathbf{G + 2 4}$}

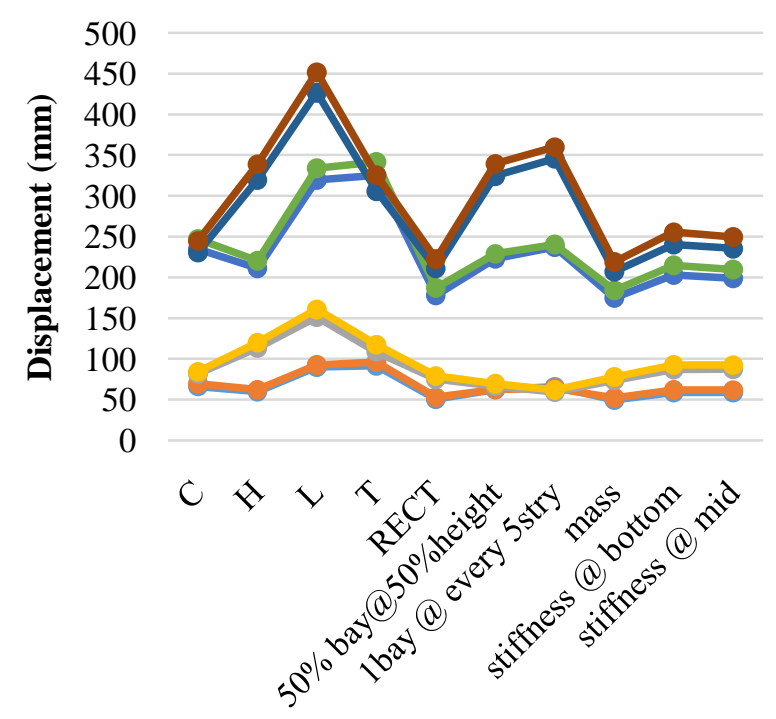

IRREGULARITIES

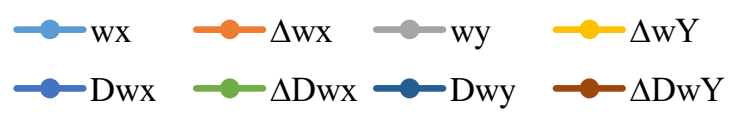

Fig 20.Static and dynamic analysis displacement of $\mathrm{G}+24$ for all irregularities

\section{$\mathbf{G + 2 9}$}

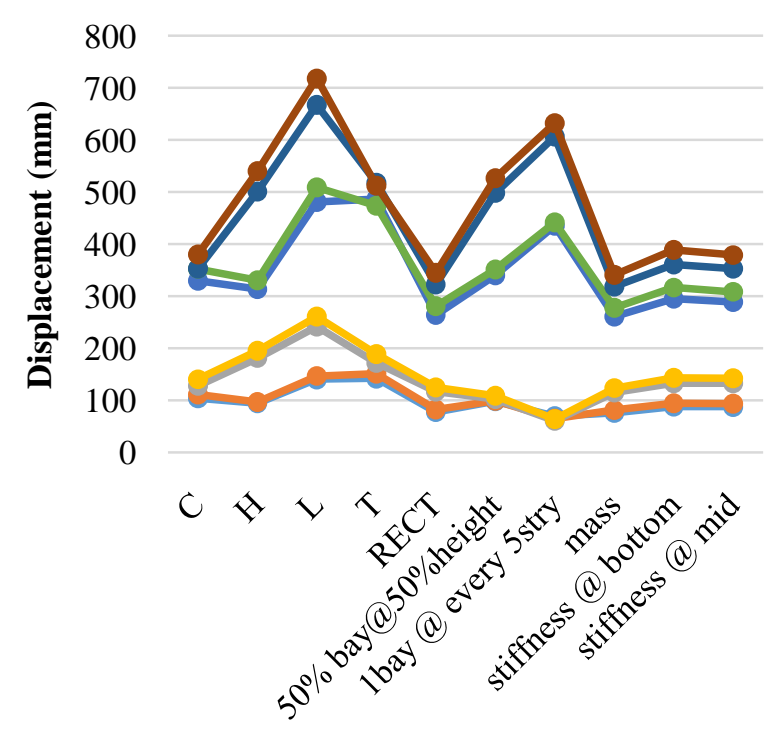

Irregularities

$$
\begin{aligned}
& \rightarrow \text { wx } \rightarrow \Delta \mathrm{wx} \rightarrow \mathrm{wy} \rightarrow \Delta \mathrm{wY} \\
& \rightarrow \text { Dwx } \multimap \Delta \text { Dwx } \multimap \text { Dwy } \multimap \Delta \text { DwY }
\end{aligned}
$$

Fig 21.Static and dynamic analysis displacement of G+29 for all irregularities

\subsection{Moments}

\section{G+9}

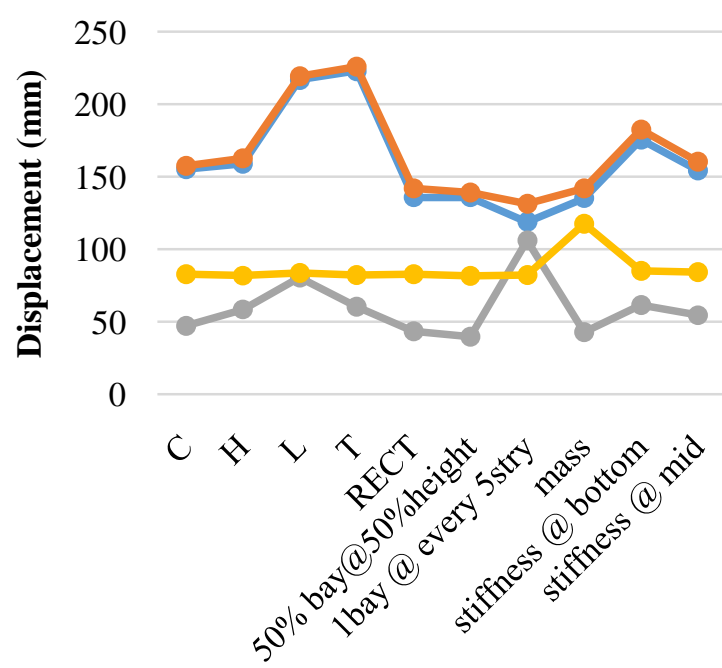

Irregularities

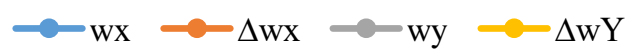

Fig 22.Static and dynamic analysis moment of G+9 for all irregularities

\section{G+14}

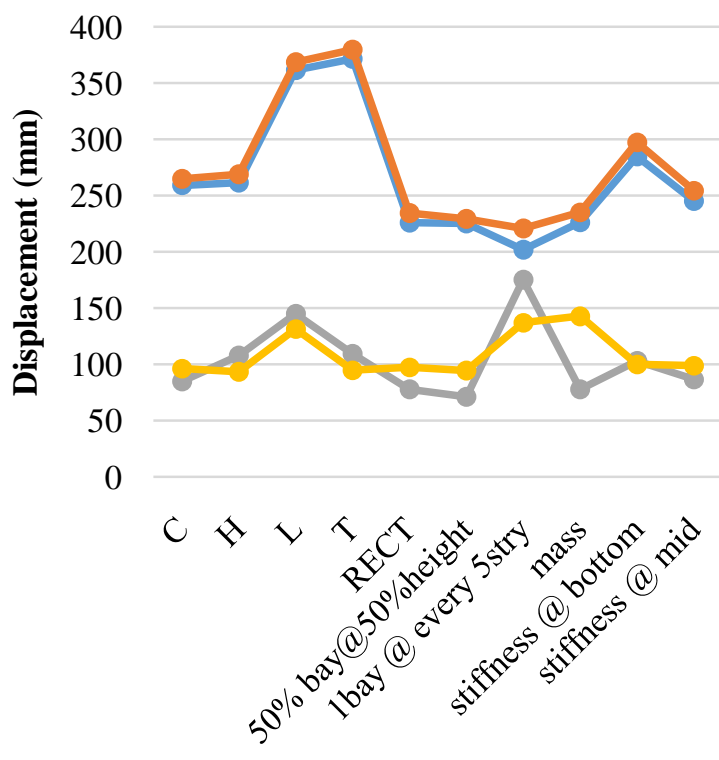

\section{Irregularities}

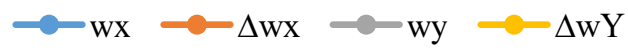

Fig 23.Static and dynamic analysis moment of $\mathrm{G}+14$ for all irregularities 


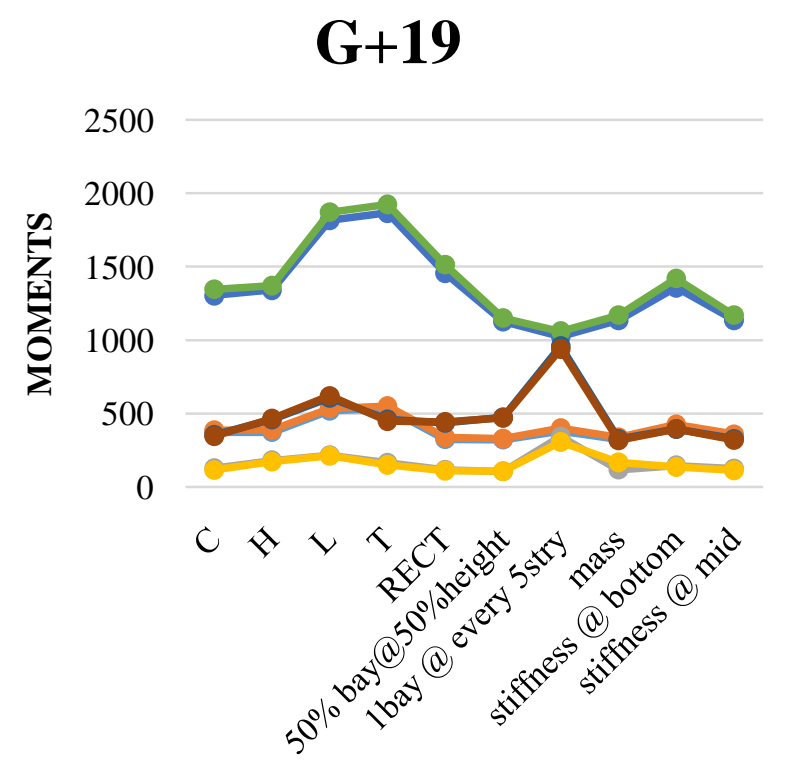

IRREGULARITIES

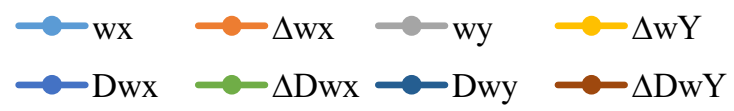

Fig 24.Static and dynamic analysis moment of $\mathrm{G}+19$ for all irregularities

\section{$\mathbf{G + 2 4}$}

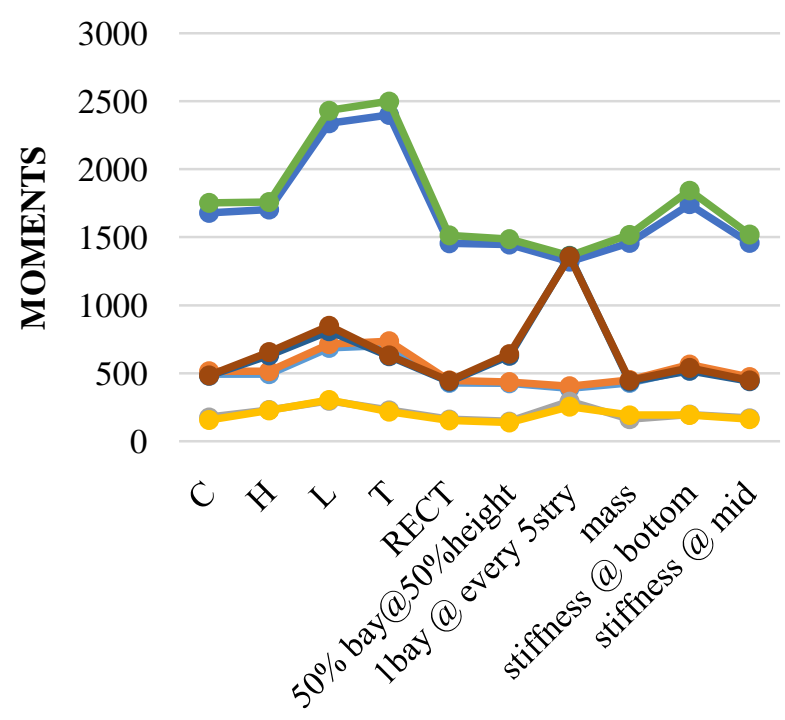

IRREGULARITIES

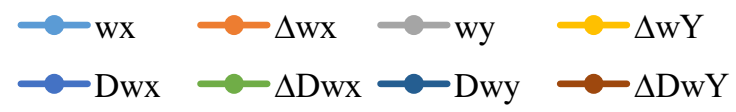

Fig 25.Static and dynamic analysis moment of $\mathrm{G}+24$ for all irregularities

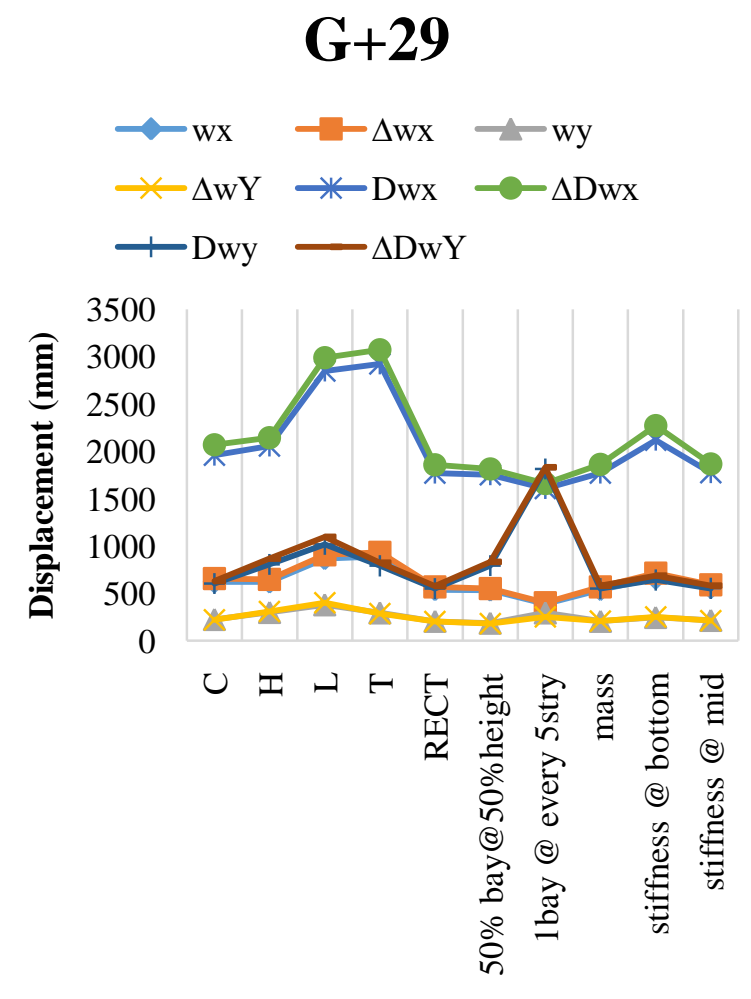

Irregularities

Fig 26.Static and dynamic analysis moment of $\mathrm{G}+29$ for all irregularities

\section{CONCLUSION}

1. From this study it has been concluded that it is important to consider the effect of $\mathrm{P} \Delta$ for high rise buildings even for wind loads and compulsory when the structure consists of structural irregularities.

2. It was observed to consider the effect of $\mathrm{P} \Delta$ from 20 storey and above or a minimum height of $65 \mathrm{~m}$ and height less than that is negligible.

3. High rise structures with irregular structural configuration are prone to severe damage than simple regular structures during high wind loads.

4. High rise buildings have to be designed for hurricane wind loads conditions along with the considerations of P $\Delta$ effect.

5. Dynamic analysis (Gust factor method) is the most realistic, reliable and accurate theoretical method of analyzing high rise structure for wind loads, and it is very essential for all such structures to undergo dynamic analysis if the structure has irregular configurations, and was observed $70 \%$ more stresses than static analysis.

6. Structures with stiffness irregularities and $\mathrm{T}$ shape plan irregularity is the weakest zone, which is $40 \%$ more weaker compared to conventional structures.

7. Structure with plan irregularities i.e. irregular shapes and extreme projections projecting away from the core or center of gravity are subjected to torsional moments of due to the gust movements of wind in windward and leeward faces of the structure, which is a major consideration in tall structures. 
8. The moments, displacement and the stress coming on the OMRF structure is high, in such conditions it is very important to use special stabilization techniques like shear walls ,dampers, bracings etc. to reduce the effect up to some extent and to overcome the primary and second order stress coming on the structure.

\section{FUTURE SCOPE}

1. To study the behavior of the structures for higher storey structures and combination of structural irregularity configurations.

2. To study the combination effect of second order stress ( $\mathrm{P} \Delta$ effect) coming from wind load and seismic load.

\section{REFERENCES}

[1]. NEERAJ KULKARNI, S.M.MAHESWERAPP, DR.J.K.DATTATRAYA, "Study of P-Delta Effect on Tall Steel Structure"

[2]. RAFAEL SHEHU, "The p- $\delta$-ductility effect: overview the effectof the second order in the ductile structures"

[3]. MALLIKARJUNA B.N, RANJITH "Stability analysis of steel frame structures: p-delta analysis"

[4]. A.S. MOGHADAM and A. AZIMINEJAD "Interaction of torsion and p-delta effects in tall buildings"

[5]. S MONISH,Mrs. S KARUNA "EFFECT OF STRUCTURAL IRREGULARITIES ON THE PERFORMANCE OF RC FRAME STRUCTURE DURING EARTHQUAKE"

[6]. MD IRFAN SHAH KHAN, Dr. B.K. RAGHUPRASAD, .AND Dr. AMARNATH K, "p-delta effects in tall reinforced concrete buildings"

[7]. RAFAEL SHEHU "The P-Delta-Ductility effect: Overview the effect of the Second Order in Ductile Structures.

[8]. IS: 875 (Part 1)-1987 Code of practice for design loads (Other than Earthquake) for buildings and structures, Bureau of IndianStandard, New Delhi, India.

[9]. BIS Code, IS 875 (Part 3)-1987. "Code of Practice for design loads (other than earthquake) for building and structure", Part 3, Wind loads. BIS, ManakBhawan, New Delhi, India.

[10]. IS 1893 (PART1)-2002 "Criteria for Earthquake Resistant Design of Structures BIS, ManakBhawan, New Delhi, India.

[11]. N.SUBRAMANIAN “Design of Steel Structures”. 